\title{
Discricionariedade administrativa e eutanásia animal em unidade de vigilância de zoonoses: um estudo de caso
}

\author{
Administrative discretion and animal euthanasia in zoonoses surveillance units: a case \\ study
}

Discricionariedad administrativa e eutanásia animal en unidades de vigilancia de zoonosis: un estudio de caso

Camila da Silva ${ }^{1}$

André Freccia ${ }^{2}$

Mauro Maciel de Arruda $^{3}$

RESUMO: A discricionariedade do poder público para a prática da eutanásia em animais nas Unidades de Vigilância de Zoonoses (UVZ`s) em prol da saúde pública é tema de muita discussão. Este artigo apresenta um estudo de caso sobre a prática de eutanásia ocorrido em uma Unidade de Vigilância de Zoonose na cidade de Belo Horizonte/MG, visando analisar a discricionariedade pública e o processo da eutanásia bem como as legislações que permeiam as UVZ`s para executar tal processo em cães errantes.

Palavras-chave: Zoonoses. Eutanásia. Direito a Saúde.

ABSTRACT: The discretion of the public authority for the practice of euthanasia in animals in the Zoonoses Surveillance Units (ZSU's) in favor of public health is the subject of much discussion. This article presents a case study on the practice of euthanasia that occurred in a Zoonoses Surveillance Unit in the city of Belo Horizonte/MG, aiming to analyze the public discretion and the process of euthanasia as well as the laws that permeate the ZSU's to execute such a process in stray dogs.

Keywords: Zoonoses. Euthanasia. Right to Health.

RESUMEN: La discrecionalidad del poder público para la práctica de la eutanasia en animales en las Unidades de Vigilancia de Zoonosis (UVZ`s) en pro de la salud pública es tema de mucha discusión. Este artículo presenta un estudio de caso sobre la práctica de eutanasia ocurrido en una Unidad de Vigilancia de Zoonosis en la ciudad de Belo Horizonte / MG, buscando analizar la discrecionalidad pública y el proceso de la eutanasia así como las legislaciones que permean a las UVZ`s para ejecutar tal proceso en perros errantes.

Palabras-Ilave: Zoonosis. Eutanasia. Derecho a la Salud.

\footnotetext{
${ }^{1}$ Médica Veterinária. Criciúma - Santa Catarina. Brasil. E-mail: miillaa@gmail.com

${ }^{2}$ Mestre em Zootecnia. Professor do Curso de Medicina Veterinária, Agronomia e Pesquisador do Núcleo de Pesquisa e Extensão Aplicadas às Ciências Agroveterinárias (PACA). UNIBAVE. Orleans - Santa Catarina. Brasil. E-mail: andrefreccia@gmail.com

${ }^{3}$ Doutor em Medicina Tropical. Professor do Curso de Medicina Veterinária e Pesquisador do Núcleo de Pesquisa e Extensão Aplicadas às Ciências Agroveterinárias (PACA). UNIBAVE. Orleans - Santa Catarina. Brasil. E-mail: mauroarruda1@hotmail.com
} 


\section{Introdução}

Compreende-se por discricionariedade do poder público, a vontade legítima de decisão, com base em uma avaliação sobre qual a melhor solução para o caso concreto, isto é, somente quando não há solução determinada. Essa vontade legítima não é exercida de forma liberal e sim pautada nas atribuições que a lei confere (1). Percebe-se que a discricionariedade é um poder, o qual se caracteriza da seguinte forma:

A discricionariedade é um modo de construção da norma jurídica, caracterizado pela atribuição ao aplicador do encargo de produzir solução por meio de ponderação quanto às circunstancias. Ou seja, a discricionariedade significa que a lei atribui ao aplicador o dever-poder de realizar a escolha (2).

Evidencia-se nesse conceito uma certa margem de livre análise para o que for melhor conveniente e oportuno para cada solução legalmente admissível. Desta maneira, o poder discricionário deve ser efetuado de forma que atenda o interesse público, de acordo com a alçada que Ihe foi dada.

Conclui-se, assim, que no poder discricionário a vontade de quem aplica a solução ao caso é legitimada pelo direito, que nesses casos não tem uma solução que determina o que fazer no caso específico, assim o aplicador da discricionariedade, aplica o que julga ser melhor para solucionar o "problema" (2).

A eutanásia é uma prática antiga, Francis Bacon, no ano de 1623, utiliza a expressão pela primeira vez em sua obra História vitae et mortis, nela o filósofo defendia que os médicos deveriam ter a habilidade de mitigar através das mãos os sofrimentos e agonia da morte (3).

O Dicionário Prático da Língua Portuguesa Michaelis define "eutanásia":1. sf Med. Morte serena sem sofrimento. Em um estudo mais profundo da palavra, o autor Figueiredo discorre a etimologia do vocábulo como proveniente do grego EU (bom, boa) + THANAT[O] (morte) significando assim, boa morte (4).

A eutanásia não dever ser confundida com sacrifício, eles são diferentes:

Atualmente, entende-se como sacrifício de animais o processo de morte causado por métodos como câmara de gás, eletrochoque, disparo de armas e outros que inflijam dor ou agonia ao morrer, e eutanásia - a morte em que o animal é submetido à sedação ou anestesia e posterior indução à morte 
pela injeção de substância, como o cloreto de potássio, em dose letal. Pela etimologia, eutanásia significa boa morte; morte digna (5).

Esclarecido o significado de discricionariedade do poder público, a etimologia e conceito de eutanásia é relevante que seja exposto o papel da Unidade Vigilância de Zoonoses (antigamente denominados Centro de Controle de Zoonoses) que no passado devido a situação epidemiológica da raiva no ciclo urbano tinhas suas ações voltadas para recolhimento, vacinação e eutanásia de cães visando o controle da raiva (6).

No Brasil, hoje, existem aproximadamente 277 Unidades de Vigilância de Zoonoses (6) que de acordo com a Portaria no 1.138 do Ministério da Saúde (2014) tem função a prática de ações direcionadas para Vigilância, Prevenção e Controle de Zoonoses e de Acidentes causados por Animais Peçonhentos. Tendo como exemplo a Leishmaniose canina, Leptospirose, Raiva, dentre outros (7).

No contexto dessa pesquisa, as atividades da Administração Pública são de essencial compreensão. Isso tendo em vista a questão da discricionariedade do poder público para a autorização da prática de eutanásia em animais abrigados em Unidades de Vigilância de Zoonoses. A questão central é verificar os limites da discricionariedade do poder público, neste caso, salvaguardando os direitos dos animais.

\section{Fundamentação teórica}

De acordo com IBGE no ano de 2013, estima-se que no Brasil havia cerca de 52,2 milhões de cães domiciliados e 22,1 milhões de gatos domiciliados, ou seja, animais que possuíam um tutor. No Mundo, ainda segundo o IBGE no mesmo referido ano havia 360,8 milhões de cães e 271,9 milhões de gatos, levando o Brasil a ser o $2^{\circ}$ maior país em população média de cães e gatos.

O levantamento do número de animais errantes apresenta dificuldade metodológicas de aplicação, devido à dificuldade de avaliar e classificar a população canina e gatos (8) desta forma a Organização Mundial da Saúde estima que a população canina alcance um número de 10 a $20 \%$ da população humana (9), o Brasil sendo responsável por 30 milhões de cães e gatos errantes, do qual 10 milhões são gatos e 20 milhões são cães (10). 
O crescimento dessa população de cães e gatos em consequência da posse irresponsável e da procriação descontrolada tem constituído um problema social no decorrer dos anos. Destacando o papel histórico dessa espécie no processo de transmissão de epizootias e zoonoses como, raiva, leptospirose, dentre outros. (11).

Sendo assim, o Brasil tem implantado e estruturado em vários municípios e regiões metropolitanas unidades com a responsabilidade de executar atividades de controle de zoonoses. No início da década de 70 , as atividades dessas unidades foram intensificadas e ampliadas de forma gradativa, com a criação dos primeiros Centros de Controle de Zoonoses (CCZ) que eram voltados para o recolhimento, a vacinação e a eutanásia de cães visando controlar doenças relacionadas a saúde pública. (6).

No decorrer dos anos, a rotina dessas unidades ganhou novos programas relacionados a saúde pública, como entomologia (relativo a insetos), controle de roedores, de animais peçonhentos e de vetores (transmissores), ficando esse último a cargo das atividades de controle de endemias que eram realizadas principalmente pela Fundação Nacional de Saúde (Funasa). (6)

O Ministério da Saúde (MS), na década de 90, dispôs aplicações dos recursos em apoio aos municípios na criação e funcionamento de unidades de vigilância de zoonoses integradas ao Sistema Único de Saúde (SUS). Localizadas sobretudo em regiões metropolitanas, capitais, municípios sedes de regionais de saúde, municípios fronteiros e municípios mais populosos, essas unidades foram denominadas de Unidades de Vigilância de Zoonoses (UVZ), de acordo com a Portaria MS/SAS no 758, de 26 de agosto de 2014.

A análise do mapa de distribuição das Unidades de Vigilância de Zoonoses - UVZ, por Unidade Federada, no ano de 2015 mostra 277 municípios brasileiros com UVZ. (Figura 1).

No ano de 2014 foram publicadas normas técnicas relativas às atividades e serviços públicos de saúde voltados para a vigilância de zoonoses, conforme Portaria MS/GM nº 1.138, de 23 de maio de 2014. Teve como objetivo intensificar e aprimorar as atividades dessas unidades de vigilância, prevenção e controles de zoonoses e também de acidentes causados por animais venenosos e peçonhentos, de importância para a saúde pública, executadas pelas Unidades de Vigilância de Zoonoses e pela área de vigilância dos municípios. (6). 
Com advento da portaria MS/GM no 1.138, de 23 de maio de 2014, o Ministério da Saúde restringiu a ação de controle populacional por meio das Unidades de Vigilância de Zoonose apenas em situações que sejam caracterizados como riscos para a saúde pública.

Já em relação aos sadios, hostis e que não representem risco a saúde pública, seus proprietários devem ser orientados a buscar auxilio em estabelecimentos veterinários que tenham como objetivo o cuidado com animais. (6).

É pertinente às UVŽs o recolhimento de animais (vivos ou mortos) de risco para a saúde pública, isso, claro, de forma seletiva, tendo o cuidado de avaliar se realmente o animal está de acordo com a MS/GM n 1.138, de 23 de maio de 2014, tratando -se de um "animal de relevância para a saúde pública". O mesmo procedimento deve ser realizado com a recepção de animais (vivos e mortos) entregues pela população, sendo o médico veterinário e/ou responsável técnico quem fará a avaliação desses animais, usando de procedimentos (triagem) e documentações (atestados ou laudo médico veterinário) necessários para a seleção.

No caso de animais mortos relevantes para a saúde da população, o cadáver deverá ser encaminhado para necropsia, já os animais vivos depois de avaliados e se constatado risco imediato de transmissão de zoonose e relevante para a saúde pública, deverá ser recolhido para observação e coleta de amostras para verificação laboratorial ou submetido à eutanásia, isso, visando sempre a possível gravidade da doença, as normas técnicas para o controle de zoonoses e a legislação vigente. (6).

Conforme recomendações do Conselho Federal de Medicina Veterinária (12) e do Ministério da Saúde (6), o procedimento da eutanásia as UVZ devem seguir alguns critérios e/ou normas, como: possuir espaço adequado, materiais em quantidade necessária, profissionais capacitados, e realização de controle através de registros.

O método escolhido para a prática da eutanásia deverá considerar sempre a espécie animal, a idade, o estado fisiológico do animal e a quantidade de animais envolvidos no processo. O método ainda deverá reputar a segurança do executor, a segurança e confiança da execução. A morte do animal deverá ser comprovada sempre, por meio de declaração de óbito redigida pelo médico veterinário responsável (12).

Ainda se tratando da resolução 1000/12 do Conselho Federal de Medicina Veterinária, que dispõe sobre os procedimentos e métodos de eutanásia em animais e da 
outras providências, alguns procedimento são elencados e que merecem atenção: a prática ou a supervisão desde procedimento deverá ser realizado exclusivamente pelo profissional médico veterinário, assim também como a compra de drogas e seu armazenamento, seguindo os preceitos da legislação municipal, estadual e federal; a prática da eutanásia se mal empregada está submetida à legislação federal de crimes ambientais.

A Lei 9605/98 que dispõe sobre as sanções penais e administrativas derivadas de condutas e atividades lesivas ao meio ambiente, e dá outras providências, em seu artigo $32^{\circ}$, caracteriza crime, sob pena de detenção, de três meses a um ano e multa, atos de abuso, maus-tratos, ferir ou mutilar animais silvestres, domésticos ou domesticados, nativos ou exóticos. (13).

Diante disso, para que a prática da eutanásia não seja classificada como crime, deverá seguir algumas normas pré-estabelecidas pela legislação brasileira com a finalidade de normatizar o processo de eutanásia em unidades de vigilância de zoonoses, ou lugares, tal como as universidades que usam animais para experimento.

O Conselho Federal de Medicina Veterinária na resolução ํㅡ 1.000, de 11 de maio de 2012, discursa a respeito de quem pode efetuar a eutanásia animal, em que circunstâncias esse procedimento pode ser realizado e quais espécies envolvidas no processo. O bem-estar do animal deve ser sempre considerado, para que o mesmo não sofra, não sinta dor, ou caso sinta que seja a mínima possível. O artigo $3^{0}$ da citada resolução elenca que o processo da eutanásia poderá ser realizado quando:

I - o bem-estar do animal estiver comprometido de forma irreversível, sendo um meio de eliminar a dor ou o sofrimento dos animais, os quais não podem ser controlados por meio de analgésicos, de sedativos ou de outros tratamentos;

II - o animal constituir ameaça à saúde pública;

III - o animal constituir risco à fauna nativa ou ao meio ambiente;

IV - o animal for objeto de atividades científicas, devidamente aprovadas por uma Comissão de Ética para o Uso de Animais - CEUA;

$\mathrm{V}$ - o tratamento representar custos incompatíveis com a atividade produtiva a que o animal se destina ou com os recursos financeiros do proprietário. (14). 
Vejamos na figura 2, disposta na resolução 1000/12 do CFMV, os métodos legais aplicáveis e aceitos sob restrições para eutanásia de acordo com a espécie e a quantidade. Para corroborar com o presente objetivo do trabalho, apenas será exposto a parte da que está relacionada a cães e gatos.

O guia brasileiro de boas práticas para eutanásia em animais (15) discorre sobre os métodos legais aplicáveis da eutanásia, e esses estão divididos em Métodos Químicos, que englobam procedimento feitos com agentes injetáveis (sendo este o método de escolha), tendo como a principal via de aplicação a intravenosa, pois possui efeito rápido e eficaz, outros meios também podem ser citados como o uso de barbitúricos, agentes injetáveis, agentes complementares, bloqueadores neuromusculares, temos ainda o método por anestesia inalatória.

Além do mais existem outros meios como os Métodos Físicos, que incluem método mecânico como eletrocussão (podendo ser utilizado em pequenos animais), pistola de ar comprimido, deslocamento cervical, exsanguinação, dentre outros, que não são utilizados para pequenos animais e sim geralmente voltados para animais de produção. (12).

Dos métodos acima elencado vejamos o que discorre no artigo $14^{\circ}$ da resolução 1000/12:

[...]§ 1ำ Para os fins desta Resolução, métodos aceitáveis são aqueles que, cientificamente, produzem uma morte humanitária, quando usados como métodos exclusivos de eutanásia. $\S 2^{\circ}$ Para os fins desta Resolução, métodos aceitos sob restrição são aqueles que, por sua natureza técnica, ou por possuírem um maior potencial de erro por parte do executor, ou por apresentarem problemas de segurança, ou por qualquer motivo não produzam uma morte humanitária. Tais métodos devem ser empregados somente diante da total impossibilidade do uso dos métodos aceitáveis, constantes do Anexo I desta Resolução. (12).

Sob o viés da resolução 1000/12, no artigo 15 parágrafo único, que discursa sobre os métodos não aceitos para a realização da eutanásia podem ser elencado como a embolia gasosa, traumatismo, incineração in vivo, dentre outros, sendo a realização dos métodos discorridos neste artigo considerados infração ética, e os casos omissos devem ser tratados como predito no artigo 14․ De acordo com o artigo 16ํㅜ da resolução o médico veterinário está sujeito responder por processo ético profissional, caso não observe as regras e princípios determinados na resolução 1000/12. (12). 


\section{Procedimentos Metodológicos}

A escolha do tema abordado, deu-se pela relevância do assunto quanto as políticas de saúde pública e bem-estar animal, tendo em vista que a Ação Civil Pública ${ }^{4}$, objeto deste estudo de caso, abordou situação legal vivida pelo município de Belo Horizonte, qual, se utilizava de suposta prerrogativa conferida por lei, para praticar atos em discordância com a legislação nacional e tratados internacionais.

O tipo de pesquisa abordada será um estudo de caso, que tem como abordagem um objeto, que em regra procura entender o porquê de se investigar determinado caso (16), tendo como método de pesquisa utilizado o dedutivo, utilizando teorias, doutrinas e leis num geral, afim de explicar um feito particular aqui sendo a ação civil pública (17), realizado através de pesquisa qualitativa, ou seja, via escolha direta de um caso real, tendo como fundamento a pesquisa realizada sobre este caso sendo elaborada através de material bibliográfico, artigos, revistas, com a finalidade de compreender, interpretar e desvendar observando a realidade concreta do estudo de caso proposto (18).

\section{Resultados e Discussão}

Trata-se de Ação Civil Pública ofertada pelo Ministério Público do Estado de Minas Gerais, em face do Município de Belo Horizonte, no ano de 2003, visando proibição da municipalidade, em continuar a realização de eutanásia de “animais vadios”, pelo método e utilização de câmaras de gás, substituindo esse método, por outro que não provoque "dor, angustia ou sofrimento"' (6).

Em decisão de primeiro grau, a ação foi parcialmente procedente, sendo que em sua sentença, o juiz singular entendeu que o município de Belo Horizonte poderia continuar a utilizar do método de câmara de gás, desde que os animais ali postos, estivessem previamente sedados. (6).

Ato contínuo, irresignado com a decisão de primeiro grau, o Ministério Público do Estado de Minas Gerais interpôs Recurso de Apelação (segundo grau), atacando a

\footnotetext{
${ }^{4}$ Instrumento processual adequado conferido ao Ministério Público para o exercício do controle popular sobre os atos dos poderes públicos, exigindo tanto a reparação do dano causado ao patrimônio público por ato de improbidade, quanto a aplicação das sanções do artigo $37, \S 4^{\circ}$, da Constituição Federal, previstas ao agente público, em decorrência de sua conduta irregular (19).

Os legitimados para pleitear a ação civil pública são: o Ministério Público; as pessoas jurídicas de direito público interno (União, Estados, Distrito Federal e Municípios), bem como suas entidades paraestatais, porque tanto estas como aquelas podem infringir normas de direito material de proteção aos bens tutelados nesta ação, expondo-se ao controle judicial de suas condutas. (20).
} 
sentença de primeiro grau, ratificando seus pedidos iniciais, não concordando com a utilização de câmara de gás, haja vista entender ser um método cruel e desumano, citando ainda, que existem outros métodos igualmente letais, que não provocam, "dor, angústia ou sofrimento" ao animal (6).

Na literatura médica veterinária, o uso de câmaras de gás são aceitos sob restrição, visto que o uso inadequado da câmara de gás, especialmente no que tange a concentração de $\mathrm{CO}_{2}$, quando em baixa concentração não serve para o fim que se destina trazendo dor e angústia ao animal, e quando em altas concentrações além de também provocar angústia e sofrimento no animal torna-se potencialmente nociva à saúde humana (executor), como nos mostra as Diretrizes da Prática de Eutanásia do Conselho Nacional de Controle de Experimentação Animal - CONCEA:

Apesar de o CO2 apresentar efeito analgésico e anestésico geral em altas concentrações, não é um método humanitário para nenhuma espécie. Concentrações a partir de $40-50 \%$ são desagradáveis para os seres humanos, pois levam à formação de ácido carbônico nas mucosas e acima de $50 \%$ são nocivas. Tal fenômeno também ocorre nos animais. Em contrapartida, o tempo até a inconsciência é inversamente proporcional à concentração utilizada. Diversos efeitos adversos são observados em cães, como dispneia, ataxia, espasmos musculares, micção, salivação, defecação, contrações tônicas e convulsões, o que torna este método inaceitável nesta espécie. (21).

Após as contrarrazões do município de Belo Horizonte, foi dado provimento ao recurso do Ministério Público, sendo vencido o Desembargador Relator (4 votos x 1 voto), modificando a respeitosa sentença de primeiro grau, decretando ao ente público, o dever de usar outro método para eutanasiar cães e gatos, tal como, a injeção letal ou outro método que não cause dor ou sofrimento ao animal no momento da morte. (6).

Não concordando com a decisão de segundo grau, o Município de Belo Horizonte, entendendo que houve violação ao princípio da proibição da reformatio in pejus ${ }^{5}$ dos julgados, interpôs Recurso Especial (terceiro grau) ao Superior Tribunal de Justiça. (6).

Após os debates processuais, a Segunda Turma do Superior Tribunal de Justiça, por unanimidade negou provimento ao recurso da Municipalidade, nos termos do voto do Sr. Ministro Relator, sob o viés de que não houve violação ao princípio da proibição da

\footnotetext{
${ }^{5}$ Piora tanto quantitativa ou qualitativa na situação do Recorrente, ante a decisão recorrida e a nova decisão prolatada pelo órgão julgador, sendo esta situação vedada em nosso ordenamento jurídico. (22).
} 
reformatio in pejus, haja vista a decisão de segundo grau, atender aos princípios do bemestar animal, bem como atender aos enunciados de leis federais e tratados internacionais, os quais, o Brasil é signatário. (6).

Razão pela qual, a adoção de método letal, divergente da câmara de gás, mas que não provoque "dor, angústia ou sofrimento" ao animal, não pode ser considerado como reforma prejudicial da decisão de segundo grau, eis que é considerado um avanço, não situação prejudicial ao julgado (6).

No presente caso, a administração pública (prefeitura de Belo Horizonte) tratava os animais abandonados ou que não são reclamados nas unidades de vigilância em zoonoses (na época ainda centros de controle de zoonose) ou até mesmo os que são entregues de forma voluntária como "coisas abandonadas", e simplesmente por este fato poderiam dar-lhes o destino que achassem mais cabível.

A insistência da prefeitura de Belo Horizonte/MG em realizar a eutanásia desses animais com gás asfixiante, alegando ter legitimidade para o fazer do modo que bem pretendesse, já que "não existia lei e/ou algo específico para determinado caso, e que por isso poderia fazer o que bem entendesse com essas “coisas abandonadas", é equívoco e arbitrário, pois dentro do nosso país, existem leis e resoluções que preservam o bem-estar do animal como nossa constituição federal, decreto universal dos direitos dos animais em seu artigo $3^{\circ}$ e a lei 9.605/98, dentre outros. (6).

A utilização de câmara de gás atualmente é aceito sob restrição conforme Resolução do Conselho Federal de Medicina Veterinária 1000/12, visto que o procedimento de eutanásia, deve ocorrer de acordo com leis e resoluções já descritas, devendo ser utilizado métodos para que se evite possíveis traumas decorrentes da fase de excitação. Vale ressaltar que o uso de câmara de gás, apesar de apresentar vantagens como baixo custo, fácil aquisição, somente deve ser utilizado em casos restritos ou que não possuam outro meio legal e aceitável para assim fazê-lo, pois é uma forma de eutanásia que muitas vezes leva um tempo maior para ação do agente, em comparação com outros métodos, o que pode provocar angústia ao animal. (12).

Diante os fatos exposto acima, a prefeitura estava abusando de seu poder, deixando de lado a "boa morte" desses animais, além de que, essas eutanásias não poderem ser justificadas sendo em "prol a saúde pública", pois estes animais estavam sofrendo este processo de "eutanásia" simplesmente por ter uma superpopulação de cães e gatos 
abandonados na cidade de Belo Horizonte, onde não necessariamente estes animais teriam algum tipo de enfermidade que pudesse atingir a população, ou causar danos à saúde pública. (6).

Ressalta-se aqui que esse processo teve seu transito em julgado no ano de 2009, assim até chegar aos tribunais a prática da eutanásia utilizada ou pretendida era mais antiga, mesmo assim não podendo ser justificada por tal ato arbitrário, visto que os métodos legais para se fazer a eutanásia sempre estiveram presentes na legislação, mesmo quando esta ainda não tinha sido revogada para a resolução atual 1000/12, (anteriormente na resolução 714/02 CFMV que nem se quer aceitava eutanásia por $\mathrm{CO}_{2}$ para cães e gatos).(12).

Portanto serve de exemplo de ganho de qualidade nos procedimentos de execução das eutanásias pelos órgãos oficiais, já que atualmente a realização indiscriminada e sem justo motivo da eutanásia não podem mais serem utilizadas, bem como a utilização de câmaras de gás para cães e gatos deverem ser utilizados somente em casos que não há outro meio aceitável, adequado para realizar tal procedimento, e serão passíveis de processos administrativos e judiciais quem infringir este procedimento, pois já existem leis ou normas que garantem o direito dos animais de terem uma boa morte. (12).

Diante o exposto, fica evidente que o poder administrativo não pode abusar do seu poder discricionário para efetuar algo que seja somente em benefício próprio, e que cause danos a terceiros, que neste caso, de acordo com a decisão judicial nำ2009/0005385-2, STJ/MG os "terceiros" seriam os animais errantes daquela região. (12).

\section{Considerações Finais}

No presente caso o Superior Tribunal de Justiça - STJ entendeu que o município de Belo Horizonte/MG abusou do poder que a lei lhe confere, eutanasiando de forma indiscriminada e sem justo motivo animais abandonados e/ou de rua, afirmando que 0 controle populacional desses animais era medida de saúde pública, principalmente por se utilizar método menos aceitável ao realizar a eutanásia (câmara de gás), visto que tanto nas leis brasileiras quanto em tratados internacionais, a outros métodos iguais ou mais letais que "não provoque dor, angústia ou sofrimento ao animal", servindo este trabalho em conjunto com a decisão do STJ como fundamentação balizadora de novos estudos da 
matéria ou servindo de norte para o agente público na hora de tomar decisões quando a matéria se tratar de eutanásia animal em Unidades de Vigilância de Zoonoses - UVZ.

\section{Referências}

1. Medauar O. Direito administrativo moderno. 10.ed. São Paulo: Ed. Revista dos Tribunais. 2006.

2. Justen Filho M. Curso de direito administrativo. 2. ed. São Paulo: Ed. Saraiva. 2006. p. 159-163.

3. Campos P.B, Medeiros, G.L. A Eutanásia e o Princípio Constitucional da Dignidade da Pessoa Humana. Revista Eletrônica Direito, Justiça e Cidadania. São Roque, v.2, n 1, 2011. Disponível em: http://www.facsaoroque.br/novo/publicacoes/pdfs/patricia_drt_20111.pdf [Acesso em 20.jul. 2016].

4. Figueiredo C. Geriatria clínica dos caninos e felinos. Rio de Janeiro: Ed. Guanabara Koogan S.A. 2005. p. 77-79.

5 Bacelar S. Balão de oxigênio e eutanásia. Revista Paranaense de Medicina. Belém, v.20, n 4, p.59-60, dez. 2006. Disponível em:

http://scielo.iec.pa.gov.br/scielo.php?script=sci_arttext\&pid=S0101-59072006000400016. [Acesso em 15.jul. 2016].

6 Brasil. Ministério da Saúde. Secretaria de Vigilância em Saúde. Departamento de Vigilância das Doenças Transmissíveis. Manual de vigilância, prevenção e controle de zoonoses: normas técnicas e operacionais. 1 ed. versão eletrônica. Brasília, Ministério da Saúde, 2016. Disponível em:

http://portalsaude.saude.gov.br/images/pdf/2016/julho/08/manual-zoonoses-normas-2v7julho16-site.pdf. [Acesso em 28.jul. 2016].

7. Diretoria de Vigilância Epidemiológica. Disponível em: http://www.dive.sc.gov.br/index.php/doencas-agravos. [Acesso em 25 nov.2016].

8. Alves MCGP, Matos MR, Reichmann MDL, Dominguez MH. Dimensionamento da população de cães e gatos do interior do Estado de São Paulo. 2005. Disponível em: http://www.scielo.br/scielo.php?script=sci arttext\&pid=S0034-

$89102005000600004 \& \mathrm{Ing}=$ en\&nrm=iso\&tlng=pt\&ORIGINALLANG=pt. [Acesso em: 25 .nov. 2016].

9. Reis VGL, Rocha SM, Silva GCP. 2007.Manual de Controle da Raiva Animal e Noções de Posse Responsável para Cães e Gatos. Disponível em: 
http://www.saude.mt.gov.br/upload/documento/50/manual-raiva-[50-151009-SES-MT].pdf. [Acesso em 25.nov. 2016].

10. Farinha A. Digitais PUC - Campinas. 2014. Disponível em:

https://digitaispuccampinas.wordpress.com/2014/02/27/cresce-para-30-milhoes-o-numerode-animais-abandonados-no-brasil/. [Acesso em 26.nov. 2016].

11. Barroso JEM, Lima EE. Centro de Controle de Zoonoses e sua Importância para a Saúde Pública do Município de Catalão, GO. 2012. Disponível em:

http://www.anais.ueg.br/index.php/ciegesi/article/view/1175/889. [Acesso em 25.nov. 2016].

12. Conselho Federal de Medicina Veterinária. Resolução nํ1000, de 11 de maio de2012. Dispõe sobre procedimentos e métodos de eutanásia em animais e da outras providencias. Disponível em: http://portal.cfmv.gov.br/portal/lei/index/id/326. [Acesso em 03.ago.2016].

13. Brasil. Lei 9.605 , de 12 de fevereiro de 1998. Dispõe sobre as sanções penais e administrativas derivadas de condutas e atividades lesivas ao meio ambiente, e dá outras providências. Disponível em: http://www.planalto.gov.br/ccivil_03/leis/L9605.htm. [Acesso em: 30. jul. 2016].

14. Brasil. Resolução no 1000 , de 11 de maio de 2012. Dispõe sobre procedimentos e métodos de eutanásia em animais e da outras providencias. Disponível em: http://portal.cfmv.gov.br/portal/lei/index/id/326. [Acesso em 03.ago.2016].

15. Brasil. Guia Brasileiro de Boas Práticas em Eutanásia em Animais - Conceitos e Procedimentos Recomendados. Brasília, v.1. 2012. Disponível em:

http://www.cfmv.gov.br/portal/_doc/guiabbp_eutan\%C3\%A1sia_animal.pdf. [Acesso em: 13. ago 2016]

16. Ventura MM. O Estudo de Caso Como Modalidade de Pesquisa. Disponível em: http://sociedades.cardiol.br/socerj/revista/2007_05/a2007_v20_n05_art10.pdf. [Acesso em 26.nov. 2016].

17. Diniz CR, Silva IB. Tipos de Métodos e Sua Aplicação. 2008 Disponível em: http://www.ead.uepb.edu.br/ava/arquivos/cursos/geografia/metodologia_cientifica/Met_Cie_ A04_M_WEB_310708.pdf. [Acesso em: 26.nov. 2016].

18. Goode W, Hatt P. Estudo de caso como procedimento de pesquisa científica. Porto Alegre, v.22, n.3, 2009. Disponível em:

http://www.scielo.br/scielo.php?script=sci_arttext\&pid=S0102-79722009000300013. [Acesso em: 26.nov. 2016].

19. Moraes A. Direito Constitucional Administrativo. 23 ed. São Paulo: Atlas, 2008.

20. Costa KC. Ação Popular e Ação Civil Pública. In: Âmbito Jurídico, Rio Grande, XIV, n. 90, jul 2011. Disponível em: http://www.ambito- 
juridico.com.br/site/?n_link=revista_artigos_leitura\&artigo_id=9888\&revista_caderno=9. Acesso em 02 dez. 2016.

21.Brasil. Conselho Nacional De Controle De Experimentação Animal- CONCEA; Ministério Da Ciência, Tecnologia e Inovação- CONCEA. Diretrizes Da Prática De Eutanásia Do Concea, 2013. Disponível em: http://www.unifesp.br/reitoria/ceua/images/Diretrizes\%20Eutanasia\%20CONCEA.pdf [Acesso em 26.nov. 2016].

22. Santos MFSN. Reformatio in pejus. Trabalho de Conclusão de Curso (Graduação em Direito) - Universidade Tuiuti do Paraná - UTP - Curitiba, Paraná, 2014. Disponível em: http://tcconline.utp.br/media/tcc/2015/05/REFORMATIO-IN-PEJUS.pdf. [Acesso em 01. dez. 2016.] 